\title{
Quality Gap of Family Health Care Services in Kashan Health Centers: An Iranian Viewpoint
}

\author{
Mohammad Sabahi Bidgoli ${ }^{1}$, Ali Kebriaei ${ }^{2^{*}}$, Sayed Gholamabas Moosavi ${ }^{3}$ \\ ${ }^{1}$ Department of Public Health, School of Health, Zahedan University of Medical Sciences, \\ Zahedan, Iran. \\ ${ }^{2}$ Department of Public Health, School of Health, Kashan University of Medical Sciences, \\ Kashan, Iran. \\ ${ }^{3}$ Department of Biostatistics and Epidemiology, School of Health, Zahedan University of Medical \\ Sciences Zahedan, Iran.
}

* (Corresponding author) Ali Kebriaei, PhD, Associate Professor. Department of Public Health, Kashan University of Medical Sciences, Qotberavandi Boulevard, Kashan, Iran.

E. mail: kebria_noosh@yahoo.com (TelFax: +98 31 55540111).

\section{Keywords: Family Health, Female, Perceptions, Iran.}

\begin{abstract}
Patients' viewpoints are commonly used to assess quality of care in diverse healthcare organizations. The purpose of the current study is to investigate quality gap of family health care through measuring differences between clients' perceptions and expectations at Kashan city health centers in Iran. A cross-sectional design was applied in 2013. The study sample was composed of 384 women clients of family health services randomly selected from Kashan city health centers. The SERVQUAL questionnaire was used for data collection. Service quality gap was measured by computing the difference between the rating respondents assign to expectations and perceptions statements. For pair wise comparison of the expectations and perceptions the Wilcoxon Signed Rank test was used. Internal consistency of the scale was confirmed with Cronbach's Alpha coefficients.In all dimensions of the services a significant $(\mathrm{P}<0.001)$ negative quality gap was observed. The maximum quality gap was in the tangibility $(-0.60 \pm 0.37)$ and the minimum one was in the responsiveness $(-0.41 \pm 0.31)$ dimension. The findings of the research demonstrated that there was negative gap between clients' expectations and perceptions in all dimensions of the services. Thus, family health care managers should apply improvements in all five dimensions of the services.
\end{abstract}

\section{Introduction}

The concept of quality, as a competitive advantage, has come from the industrial field to the service ground [1]. Since then, service quality has been receiving a good deal importance due to its clear correlation to costs [2], financial performance [3, 4], consumer satisfaction [5, 6], loyalty and customer retention [7,8]. It is hard to quantify service quality, however measuring quality of service, as a prerequisite to advance service quality and to attain customer loyalty and satisfaction, is necessary [9].

By customary means of measuring quality of goods, service quality could neither be conceptualized nor assessed because services are intangible, heterogeneous and inseparable [10]. As a result Parasuraman et al. (1985) have expanded, validated and purified an instrument called SERVQUAL to evaluate service quality [11]. SERVQUAL can highlight areas for specific action and address perceived service deficiencies [12].

The SERVQUAL, as a gap model, refer to quality of service as the differences between consumers' expectations and perceptions of service. A gap is shaped when individuals' perceptions of provided services lie behind of their expectations [11]. So that to entice customers and maintain them, scholars and managers are vigorously engaged in knowing users' expectations and perceptions of service quality and consequently developing policies to render quality services [1]. 
Furthermore, a sufficient recognition of clients' expectations - besides their past encounter permits management decisions to be made based on facts rather than conjecture in the crucial duty of conducting the people viewpoints [13].

In health care settings, failure to meet the quality needs of customers could lead to a disaster [14]. Hence, for these organizations measuring service quality and deploying quality management tools is important in several ways, including fulfilling legislative requisites, complying growing customer outlooks and satisfying them.

Some scholars argue that in the field of healthcare services concerns about quality not only relate to medical effectiveness and financial efficiency but also relate to social acceptance i.e. customer attitudes [15]. By assessing customer views, management can identify service dimensions that require more attention for improvement [16]. Thus, actual expansions in service quality are achieved when the customer perspective is taken into account [17].

SERVQUAL has been widely used in various service industries to assess service quality. SERVQUAL was applied by Wisniewski and Wisniewski (2005) in a Scottish colposcopy clinic and their finding showed that the largest negative gap was in reliability dimension [18]. Result of Sharifirad et al. (2012) study on clients of primary health care centers in Iran identified that the least mean quality gap and the highest one were in assurance and tangible dimensions respectively [19]. Zarei et al (2012) in their survey at private general hospitals in Iran found the highest and the lowest expectation and perception in tangibles and empathy dimensions respectively [20]. Boshoff and Gray (2004) identified that perception of quality of service positively correlate with patient satisfaction, willingness to recommend and intention to visit the hospital again [7].

Despite the worldwide studies on health services quality, very little research has been conducted on the family health care quality in Iran. Based on this rationale, this study aims to investigate the gap between perceived and expected quality of family health services from viewpoint of female clients to Kashan city health centers.

\section{Methodology}

A cross sectional design was applied in 2013. Out of the female clients of Kashan health centers 384 female were selected (using Krejcie and Morgan's table). Total of the health centers were considered for investigation and the samples were divided among the 16 health centers based on proportionality to the households covered. The samples were selected by simple random sampling method in each health center. The questionnaire was given to them after receiving service. The illiterate clients were interviewed by a trained interviewer. Finally, 370 of the 384 questionnaires $(96.3 \%)$ were correctly filled out and gathered for analysis.

The questionnaire was designed based on SERVQUAL scale - developed by Parasuraman et al. (1985) - that is a well-known construction for measuring quality of service in a range of service settings [21]. SERVQUAL is widely used within customer oriented organizations in both private and public settings [22], and was thus selected for this study. This measure includes 22 items about service features that can be viewed in terms of five underlying dimensions, (1) tangibles, i.e. the appearance of physical elemets; (2) reliability, that is dependable and accurate performance; (3) responsiveness, i. e. promptness and helpfullness; (4) assurance, i. e. competence, courtesy, credibility and security; (5) empathy, that is easy access, customer understanding and good communications [10].

The research instrument consisted of three sections: A selective demographic characteristics, an expectations section consisting of 22 items and a perceptions section consisting of a similar set of statements. In order to understand how clients perceive delivered services a five point scale (completely agree to completely disagree) was applied. For measuring their expectations the same scale (fully important to fully unimportant) was administered. Disagreements between perceptions and expectations showed a quality gap in each item and each dimension ( $\mathrm{QG}=\mathrm{P}-\mathrm{E})$.

To determine the validity of questions, we used content validity. To measure questionnaire's content validity, four scholars in the field of health care management inspected the scale to ascertain its consensual validity. According to their view essential corrections were made to ensure that 
questionnaires measure what authors seek. Reliability analysis for the questionnaires yielded a Cronbach's alpha of 0.91 for expectations and 0.93 for perceptions items.

The data were analyzed using SPSS for Windows (version16.0). Descriptive statistics (mean and standard deviation) were used to review demographic characteristics and level of measured variables. To compare differences of clients' expectations and perceptions the Wilcoxon signed rank test was used. $\mathrm{P}$ values less than 0.05 were considered statistically significant.

\section{Findings}

Findings show that respondents age ranged from 18 to 48 years with an average of $30.04 \pm 7.6$ years. About $37 \%$ of females were illiterate or only could read and write, $29 \%$ had completed secondary education, while the remainder had gained a tertiary education degree.

Females' expectations and perceptions significantly were different from each other in all the five dimensions. Responsiveness and tangibility got the most and least mean scores respectively as perceived by respondents.

Respondents' expectations clearly show that the most and least expectations mean scores were in the assurance and empathy dimensions respectively. As the quality gap was calculated it is obvious that the smallest quality gap mean score was in the responsiveness and the greatest one was in the tangibility (Table 1).

Output of wilcoxon test showed that significant differences were present between females' expectations and perceptions $(\mathrm{z} \leq-10.48, \mathrm{P}<0.001)$. This leads us to the fact that there exist quality gaps in family health services at Kashan health centers.

Table 1. Descriptive statistic of service dimensions.

\begin{tabular}{llllll}
\hline Dimensions & Expectation & Perception & Quality gap & Wilcoxon test $(\mathrm{z})$ & P Value \\
\hline Tangibility & $4.49 \pm 0.56$ & $3.89 \pm 0.50$ & $-0.60 \pm 0.37$ & -14.55 & $<0.001$ \\
\hline Reliability & $4.49 \pm 0.54$ & $3.96 \pm 0.51$ & $-0.53 \pm 0.26$ & -11.88 & $<0.001$ \\
\hline Responsiveness & $4.51 \pm 0.57$ & $4.10 \pm 0.55$ & $-0.41 \pm 0.31$ & -11.47 & $<0.001$ \\
\hline Assurance & $4.58 \pm 0.54$ & $4.09 \pm 0.52$ & $-0.49 \pm 0.29$ & -11.98 & $<0.001$ \\
\hline Empathy & $4.37 \pm 0.68$ & $3.92 \pm 0.57$ & $-0.45 \pm 0.21$ & -10.48 & $<0.001$ \\
\hline
\end{tabular}

According table 2, two out of the five highest expectations means are in the tangibility, the next and the fourth highest expectations means are in the assurance. The third highest expectation mean is in the reliability dimension.

Table 2. The five items with the highest and the five items with the lowest expectations means.

\begin{tabular}{ll}
\hline Highest Expectations means & $\mathrm{M} \pm \mathrm{SD}$ \\
\hline Environment is clean and comfortable with good directional signs & $4.76 \pm 0.65$ \\
\hline Employees are friendly and courteous & $4.66 \pm 0.64$ \\
\hline When employees promises to do something by a certain time, it does so & $4.62 \pm 0.72$ \\
\hline I can trust employees of health center & $4.57 \pm 0.72$ \\
\hline Privacy during service delivery & $4.56 \pm 0.81$ \\
\hline Lowest Expectations means & $4.24 \pm 0.87$ \\
\hline Employees have patients best interest at heart & $4.31 \pm 0.81$ \\
\hline Materials and facilities are visually appealing and well-maintained & $4.36 \pm 0.81$ \\
\hline Employees are neat and professional in appearance & $4.36 \pm 0.84$ \\
\hline Employees give clients individual attention & $4.39 \pm 0.70$ \\
\hline Employees are professional and competent &
\end{tabular}


The assurance dimension includes an item with the lowest expectation mean. Two out of the five lowest expectation means are in the tangibility (the second and the third). The fourth and the fifth lowest expectation means are in the tangibility dimension (table 2).

The responsiveness dimension includes two out of the five highest perception means - the first and the fourth. The assurance dimension includes two out of the five highest perception means - the second and the fifth. The third highest perceptions mean is in the tangibility dimension (table 3 ).

Table 3. The five items with the highest and the five items with the lowest perceptions means.

\begin{tabular}{ll}
\hline Highest Perceptions means & $\mathrm{M} \pm \mathrm{SD}$ \\
\hline Attitude of employees instill confidence to clients & $4.26 \pm 0.68$ \\
\hline I can trust employees of health center & $4.18 \pm 0.63$ \\
\hline Employees are neat and professional in appearance & $4.17 \pm 0.64$ \\
\hline Employees are always willing to help clients & $4.11 \pm 0.70$ \\
\hline Patients are treated with dignity and respect & $4.10 \pm 0.62$
\end{tabular}

\section{Lowest Perceptions means}

The spent time for delivered services are appropriate $3.51 \pm 0.75$

\begin{tabular}{ll}
\hline Services carried out right the first time & $3.83 \pm 0.65$ \\
\hline Employees give clients individual attention & $3.84 \pm 0.69$ \\
\hline Privacy during service delivery & $3.88 \pm 0.63$ \\
\hline Employees have patients best interest at heart & $3.90 \pm 0.69$
\end{tabular}

Two out of the five lowest perception means are in the tangibility dimension (the first and the fourth). The second lowest perception mean is in the reliability dimension and two another lowest perception means, the third and the fifth, are in the empathy dimension (table 3 ).

The tangibility dimension includes three out of the five largest mean differences between expectations and perceptions (Quality Gap) - the first till the third. The assurance and the reliability dimensions include the fourth and the fifth quality gap means respectively (table 4).

Table 4. The five items with the highest and the five items with the lowest quality gap means.

\begin{tabular}{ll}
\hline Highest Quality Gap means & $\mathrm{M} \pm \mathrm{SD}$ \\
\hline The spent time for delivered services are appropriate & $-0.96 \pm 0.56$ \\
\hline Environment is clean and comfortable with good directional signs & $-0.84 \pm 0.27$ \\
\hline Privacy during service delivery & $-0.68 \pm 0.20$ \\
\hline Employees are friendly and courteous & $-0.61 \pm 0.42$ \\
\hline When employees promises to do something by a certain time, it does so & $-0.60 \pm 0.11$ \\
\hline Lowest Quality Gap means & $-0.19 \pm 0.09$ \\
\hline Employees are neat and professional in appearance & $-0.28 \pm 0.11$ \\
\hline Attitude of employees instill confidence to clients & $-0.31 \pm 0.21$ \\
\hline Employees are professional and competent & $-0.33 \pm 0.12$ \\
\hline Materials and facilities are visually appealing and well-maintained & $-0.39 \pm 0.18$ \\
\hline I can trust employees of health center &
\end{tabular}

The tangibility dimension includes two out of the five lowest quality gap means - the first and the fourth. The responsiveness, the reliability and the assurance dimensions include the second, the third and the fifth lowest quality gap means respectively (table 4). 


\section{Discussion}

The study findings showed that clients' expectations exceed their perception of real delivered services. Negative means gap yield in all the five dimensions and their relevant items. This implies that family health care managers should apply quality improvement initiatives in the health centers in order to promote service quality in all five dimensions and in turn eliminate or reduce those gaps. The result revealed that tangibility dimension is the most critical dimension as the largest quality gap was in it. This finding is consistent to Sharifirad et al. [19] and is different from some other studies such as Punnakitikashem et al. [23], Ramseook-Munhurrun et al. [24] and Kebriaei and Akbari [25].

Following the tangible, shortages were observed in the reliability and the assurance. Thus, these dimensions are the three most critical aspects that are - in comparison with other aspects - need more attention in the under study health centers. However, management should not neglect other aspects that reflect minor gaps. This finding is support by previous researches in the field of services [26, 27].

Responsiveness included the least quality gap which is different from some previous researches [19, $20,25,28]$. Following the responsiveness, the lowest one was in the empathy. In service organizations, customers mainly focus on the practical parts (how it is done) namely; reliability and assurance, instead of the technical elements (what is done) captured in the empathy dimension [29]. Therefore, it is not unexpected that there are lower gaps in the empathy and responsiveness. Although the health managers should pay more attention to critical dimensions such as tangibility and reliability, it is necessary to have a glance at these dimensions.

From the respondents view, assurance was the most important dimension which is consistent with some earlier studies results $[12,18]$ and is inconsistent with others [25, 30-32]. The respondents viewed the empathy as the least important dimension. This may be because of their expectations having been met to a large extent in this dimension. Our finding in this section is parallel to a number of works $[24,25,28]$ whereas is not consistent with some other studies [9, 18-20].

As a part of effective provision of quality services it is necessary to be aware of customer expectations. This is also essential for survival in a competitive environment [9]. In general, women's expectations were not met in the health centers. In case of high customer expectations, organization must make extra efforts to meet those expectations. Furthermore, management of customers' expectations and meeting their expectations and even exceeding their expectations is a crucial element to improve perception of service quality $[11,33]$. Curry and Sinclair argue that one of the best means of attaining this is to describe the characteristics of the service and to explaining what customers can and should expect from the provider [33].

The highest perception mean score was found in Responsiveness. This finding is inconsistent with some other studies [23, 25, 28]. Similar to finding of Sharifirad et al. [19], tangibility included the least perceptions mean score. This finding is different from the work of other researchers [14, 20, 25]. High perception scores in responsiveness dimension make it obvious that clients somewhat feeling that are given prompt services, staffs are ever tend to help them and could to respond them, and staffs' attitude instill confidence to them.

There are some limitations in applying questionnaire based studies. One of the limitations of the SERVQUAL model is that the five dimensions assessed do not capture context specific aspects of the services. Moreover, women's assessment of services quality is likely to vary between different encounters. Hence, it is suggested that in upcoming researches were used both quantitative and qualitative methods in order to give a better perspective of the multifaceted topic of quality in the health field.

\section{Conclusions}

Negative mean gaps in all the 22 items and all the five dimensions can be used as a guide for the managers of the health centers and based on it quality improvement initiatives are designed and be implemented. Generally, when we think over these items jointly convey some key messages from 
clients to care givers: be on time in service delivery and deliver prompt services, be friendly and courteous, understand the specific needs of your clients and most of all, give enough time to respond to their requests. We conclude that the tangibility is the most critical dimension. Thus it is necessary family health care managers primarily allocate limited resources to this dimension. Although, in order to improve standards of care, management should be looking carefully at each of the dimensions where women perceive that they are receiving a different service than expected and consider the extent to which they should work on influencing expectations or perceptions, or both.

\section{Acknowledgement}

We would like to express our sincere thanks to all the females for their participation in the project. We would like to show our gratitude to all those who helped in implementation of the study.

\section{References:}

[1] S. Pariseau, J. McDaniel, Assessing service quality in schools of business, International Journal of Quality \& Reliability Management. 3 (1997) 204-218.

[2] A. Wilson, V. Zeithaml, M. Bitner, D. Gremler, Services marketing: Integrating customer focus across the firm: McGraw Hill Inc. NY, 2008.

[3] R. Rust, T. Keiningham, S. Clemens, A. Zahorik, Return on quality at chase Manhattan Bank, Interfaces. (1999) 62-72.

[4] M. Sohail, Service quality in hospitals: More favorable than you think, Managing Serv Qual. 3 (2003) 197-206.

[5] N. Johns, T. Avci, O. Karatepe, Measuring service quality in travel agents: Evidence from Northern Cyprus, The Service Industries J. 3 (2004) 82-100.

[6] A. Kara, S. Lonial, M. Tarim, S. Zaim A paradox of service quality in Turkey: The seemingly contradictory relative importance of tangible and intangible determinants of service quality, Eur Bus Rev. 1 (2005) 5-20.

[7] C. Boshoff, B. Gray, The relationship between service quality, customer satisfaction and buying intentions in the private hospital industry, South Afr J Bus Manage. 4 (2004) 27-37.

[8] M. Hocutt, Relationship dissolution model: antecedents of relationship commitment and the likelihood of dissolving a relationship, International Journal of Service Industry Management. 2 (1998) 189-200.

[9] L. Douglas, R. Connor, Attitudes to service quality - the expectation gap, Nutrition \& Food Science. 4 (2003) 165-172.

[10]T. Juwaheer, Exploring international tourists' perceptions of hotel operations by using a modified SERVQUAL approach - a case study of Mauritius, Managing Service Quality. 5 (2004) 350-364.

[11]A. Parasuraman, V. Zeithaml, L. Berry, A conceptual model of service quality and its implications for future research, Journal of Marketing. 49 (1985) 41-50.

[12]M. Ahuja, S. Mahlawat, R. Zehra Masood, Study of service management with SERVQUAL model: An empirical study of GOVT/NGO'S eye hospitals in Haryana, Indian Journal of Commerce \& Management Studies. 2 (2011) 310-318.

[13]M. Donnelly, M. Wisniewski, J. Dalrymple, A. Curry, measuring service quality in local government: The SERVQUAL approach, International Journal of Public Sector Management. 7 (1995) 15-20.

[14]M. Butt, E. de Run, Private healthcare quality: applying a SERVQUAL model, International Journal of Health Care Quality Assurance. 7 (2010) 658-673.

[15]G. Al-Qatari, D. Haran, Determinants of users' satisfaction with primary health care settings and services in Saudi Arabia, International Journal for Quality in health care 6 (1999) 523-531.

[16]P. Lim, N. Tang, A Study of patients' expectations and satisfaction in Singapore hospitals, International Journal of Health Care Quality Assurance. 7 (2000) 290-299. 
[17]A. Thompson, R. Sunol, Expectations as determinants of patient satisfaction: concepts, theory and evidence, Int J Qual Health Care. 2 (1995) 127-141.

[18] M. Wisniewski, H. Wisniewski, Measuring service quality in a hospital colposcopy clinic. Int J Health Care Qual. 18:3 (2005) 217-229.

[19] G. Sharifirad, M. Shamsi, A. Pirzadeh, P. Farzanegan, Quality gap in primary health care services in Isfahan: Women's perspective, Journal of Education and Health Promotion. 1 (2012) 45-50.

[20]A. Zarei, M. Arab, A. Rahimi Froushani, A. Rashidian, S. Ghazi Tabatabaei, Service quality of private hospitals: The Iranian patients' perspective, Health Services Research. 12:1 (2012) 31 .

[21]A. Parasuraman, V. Zeithaml, L. Berry, SERVQUAL: A multiple item scale for measuring consumer perceptions of service quality, Journal of Retailing. 1 (1988) 12-40.

[22]L. Galloway, Quality perceptions of internal and external customers: a case study in educational administration, The TQM Magazine. 1 (1998) 20-26.

[23]P. Punnakitikashem, N. Buavaraporn, P. Maluesri, K. Leelartapin, Health care service quality: case example of a hospital with lean implementation. POMS 23 rd Annual Conference (2012) April 20 to April 23; Chicago, Illinois, U.S.A.

[24]P. Ramseook-Munhurrun, S. Lukea-Bhiwajee, N. Perunjodi. service quality in the public service, International Journal of management and Marketing research. 1 (2010) 37-50.

[25]A. Kebriaei, F. Akbari, Quality gap of primary health care services at Kashan District Health Centers, Iran. Journal of Medical Sciences. 3 (2006) 393-399.

[26]A. Lobo, V. Jain, Port users' perspective of the container transshipment business: hierarchy of service quality attributes and dimensions, Singapore Maritime and Port Journal. 5:1 (2002) 154-161.

[27]C. Ugboma, I. Callistus, I. Ogwude, Service quality measurements in ports of a developing economy: Nigerian ports survey, Managing Service Quality. 6 (2004) 487-495.

[28]A. Mohammadi, J. Mohammadi, Evaluating quality of health servicees in health centers of Zanjan district of Iran, Indian J Public Health. 4 (2012) 308-313.

[29]A. Mei, A. Dean, C. White. Analysis of service quality in the hospitality industry, Managing Service Quality. 2 (1999) 136-143.

[30]C. Bakar, S. Akgun, F. AL Assaf, The role of expectations in patient assessments of hospital care, International Journal of Health Care Quality Assurance. 4 (2008) 343-351.

[31]W. Ramez, Patients' Perception of health care quality, satisfaction and behavioral intention: an empirical study in Bahrain, International Journal of Business and Social Science. 18 (2012) 131-141.

[32]F. Yesilada, E. Direktor, Health care service quality: A comparison of public and private hospitals, African Journal of Business Management. 6 (2010) 962-971.

[33]A. Curry, E. Sinclair, Assessing the quality of physiotherapy services using SERVQUAL, International Journal of Health Care Quality Assurance. 5 (2002) 197-205. 